\title{
Un-Diagnosed Depression with Suicidal Ideation/Intent among Patients Visiting Medical OPD: Depression in Disguise
}

\author{
Haleema Khatoon $^{1}$, Humaira Khalid ${ }^{1}$, Manal Fatima ${ }^{1}$, Fareed Aslam Minhas ${ }^{2}$
}

\section{ABSTRACT}

Objective: This study was aimed to calculate the prevalence rate of suicide among the patients who regularly visit medical outdoor with psychosomatic complaints. Method: We have selected 750 patients around the country and screened them for depression and suicide. Result: Data shows that the prevalence of suicide is $14.7 \%$ per 10,000 persons and rate of depression is $21.8 \%$ per 10,000 persons. Preliminary analysis shows the significant correlation between the variables $\left(0.284^{* *}\right)$, descriptive statistical analysis yielded gender (0.00), age (0.02) and employment (0.05) as a significant contributing factors towards suicide behavior. Conclusion: It is verdict that the health professionals should have in-depth consideration to the symptoms and should investigate about the patients' psychological well-being.

Keywords: Depression, suicidal ideation, medical OPD, psychiatric comorbidity, unmanaged depressive episode, Pakistan

Suicidal Behavior is defined as an act in which an individual harms himself (WHO, 2002; Maris, 2002). Suicidal behavior is the result of a complex interaction of biological, genetic, psychological, sociological and environmental factors. It is a broad term that includes death by suicide and intentional, nonfatal, self-injurious acts committed with or without intent to die. Several mental disorders, including depression, substance dependence, and schizophrenia are strong correlates of suicide. Suicidal behavior can be characterized as a spectrum that ranges from fleeting suicidal thoughts to completed suicide (Moscicki, 1997). Suicidal ideation is more common than suicide attempts or completed suicide (Marzuk, 1991). Zimmerman et al., (1995) conducted a study which revealed that $3.3 \%$ of patients in an urban primary care outpatient clinic reported suicidal ideation (Zimmerman et al., 1995). Literature support that many patients who commit suicide have seen their primary care physician within several months before their death

\footnotetext{
${ }^{1}$ Clinical Psychologist, Institute of Psychiatry \& WHO Collaborating Centre, Benazir Bhutto Hospital, Rawalpindi. Pakistan.

${ }^{2}$ Professor of Psychiatry, Head Institute of Psychiatry \& WHO Collaborating Centre, Benazir Bhutto Hospital, Rawalpindi, Pakistan

(c) 2015 I H Khatoon, H Khalid, M Fatima, F Minhas; licensee IJIP. This is an Open Access Research distributed under the terms of the Creative Commons Attribution License (http://creativecommons.org/licenses/by/2.0), which permits unrestricted use, distribution, and reproduction in any Medium, provided the original work is properly cited.
} 


\section{Un-Diagnosed Depression with Suicidal Ideation/Intent among Patients Visiting Medical OPD: Depression in Disguise}

(Murphy, 1975a), and many of these physicians were unaware of the patients' intentions or that the patients had previously attempted suicide (Murphy, 1975b). Frequently, the physician and patient had a longstanding relationship that centered on physical rather than psychiatric ailments before the patient committed suicide (Doyle, 1990; Fawcett, Clark \& Busch, 1993).

\section{Epidemiology of Suicide:}

The World Health Organization (WHO) estimates that each year approximately one million people die from suicide, which represents a global mortality rate of 16 people per 100,000 or one death every 40 seconds. It is predicted that by 2020 the rate of death will increase to one every 20 seconds. In the last 45 years suicide rates have increased by $60 \%$ worldwide. Suicide is now among the three leading causes of death among those aged 15-44 (male and female). Suicide attempts are up to 20 times more frequent than completed suicides. Although suicide rates have traditionally been highest amongst elderly males, rates among young people have been increasing to such an extent that they are now the group at highest risk in a third of all countries. The overall suicide rate is 11.2 per 100,000 persons, ranking suicide as the ninth leading cause of death (Anderson, Kochanek, \& Murphy, 1997). Although age-specific rates of suicide have consistently been highest in the elderly, the incidence of suicide among adolescents and young adults has tripled since 1955 (Fawcett, Clark \& Busch, 1993). Suicide is more common in whites and Native Americans; higher rates of suicide are reported in the Western states (Moscicki, 1997). Although $80 \%$ of persons who commit suicide are men (Moscicki, 1997), the majority of those who make nonfatal suicide attempts are women between 25 and 44 years of age (Fawcett, Clark \& Busch, 1993). A previous suicide attempt is considered the best predictor of a completed suicide (Moscicki, 1997), although this history alone cannot be used to determine which patient will ultimately commit suicide. Certain psychiatric and medical disorders appear to be associated with suicide.

\section{Psychiatric Disorders:}

Findings from psychological autopsy studies have consistently indicated that more than $90 \%$ of completed suicides in all age groups are associated with psychiatric disorders (Moscicki, 1997). Suicide is a multidimensional concomitant of psychiatric diagnoses, especially mood disorders, and is complex in both its causation and in the treatment of those at risk. Psychiatric diagnoses classically associated with completed suicide include mood disorders, schizophrenia, and addiction disorders (Harris \& Barraclough, 1997). It is not the psychiatric disorder itself that increases the risk of completed suicide, but the combination of the psychiatric disorder and a stressor (Moscicki, 1997; Rich, Young \& Fowler, 1986) and the most common psychiatric disorder associated with completed suicide is depression. The risk for suicide in patients with mood disorders (major depressive disorders and bipolar disorders) is $15 \%$, and the risk is highest in the early stages of the illness (Hawton, 1987). The suicide risk among alcoholics is similar to that in patients with mood disorders, but alcoholics tend to commit suicide late in the course of alcoholism and are frequently depressed at the time of death (Hawton, 1987). Patients with 


\section{Un-Diagnosed Depression with Suicidal Ideation/Intent among Patients Visiting Medical OPD: Depression in Disguise}

schizophrenia are more likely to commit suicide during periods of remission, when they are apt to feel depressed and hopeless, than when they are frankly psychotic (Fawcett, Clark \& Busch, 1993). Patients with panic disorder and borderline personality disorder who commit suicide also have co-morbid major depression (Fawcett, Clark \& Busch, 1993; Henriksson et al., 1993).

\section{Medical Disorders:}

Some evidence has been found of an increased risk of suicide in patients with cancer, head injury and peptic ulcer disease (Mackenzie \& Popkin, 1987). Another study (Dannenberg, 1996) reported that the risk for suicide in patients who are infected with human immunodeficiency virus is not increased at the time of initial screening for the presence of the virus. However, persons with illnesses related to acquire immunodeficiency syndrome (AIDS) are 16 to 36 times more likely to die by suicide than persons in the general population (Marzuk, 1991). Suicide among medically ill patients, including those with AIDS, rarely occurs in the absence of a co-morbid psychiatric disorder, such as major depression, substance abuse or dementia (Marzuk, 1991; Mackenzie \& Popkin, 1987).

\section{LITERATURE REVIEW}

Depression is a common disorder with high prevalence rates found in studies of hospital settings, ranging from 10 to $45.0 \%$ with an average of about 15.0\% (Finch, Ramsay \& Katona, 1992; Koenig et al., 1988). There is also evidence that the diagnosis is frequently missed by hospital physicians, in one study only $8.7 \%$ of depressed patients were identified by junior doctors (Finch, Ramsay \& Katona, 1992). Depression is a common cause of disability, among its consequences are reduced life satisfaction and quality, social deprivation, loneliness, increased use of health and home care services, cognitive decline, impairments in activities of daily living, suicide, and increased non-suicide mortality (Palsson \& Skoog, 1997). There have been few studies in medical outpatient setting. The only two of note in recent years were in Veterans Administration hospitals in America predominantly of male patients (Norris et al., 1987; Okimoto, Barnes \& Veith, 1982).

These studies gave prevalence rates of $29.0 \%$ and $38.0 \%$, respectively. It has been estimated that in the year 2000, 814000 people died by suicide worldwide (WHO, 2001). Suicide is among the 10 leading causes of death for all ages in most of the countries for which information is available. In the year 2002, "suicide attempt" contributed for $1.8 \%$ of the "global burden of disease", and it is estimated that it will reach $2.4 \%$ in 2020 (Bertolote, Fleischmann \& Leo, 2003). Suicidal ideation refers to cognitions that can vary from fleeting thoughts that life is not worth living to very concrete well thought out plans for killing oneself, to an intense delusional preoccupation with self-destruction (Goldney et al., 1989). They also reported a cumulative probability of $34 \%$ for transition from ideation to a plan, $72 \%$ from a plan to an attempt and $26 \%$ from ideation to an unplanned attempt. The more detailed and specific the plan, the greater will be the lever of risk. In a prospective study on 1958 outpatients, Beck et al. (Beck \& Steer, 1991) found that hopelessness was highly correlated with eventual suicide. In addition to hopelessness, Hendin (Hendin, 


\section{Un-Diagnosed Depression with Suicidal Ideation/Intent among Patients Visiting Medical OPD: Depression in Disguise}

Maltsberger \& Haas, 2004) identified desperation as another important factor in suicide. Desperation implies not only a sense of hopelessness about change but also a sense that life is impossible without such a change. Well identified risk factors consistently associated with completed suicide in the general population include male gender, older age, white race, widowed status, poor health (especially if painful serious illness is present), and lack of social support (Fisher, Haythornwaite \& Heinberg, 2001; Ikeda, Kresnow \& Mercy, 2001; Mann et al., 1999). Patients with previous serious attempts, a family history of completed suicide, extensive psychiatric co-morbidity, psychosis, alcohol intoxication and emotional feelings of hopelessness are also at a significantly higher risk of killing themselves (Maris, 2002). Additionally, the severity and lethality of the most serious period of sociality in a patient's history has been found to be predictive of future suicide risk (Beck et al., 1985).

\section{METHOD}

\section{Sample}

Using systematic random sampling technique, 750patients (including both gender) from Medical OPD of tertiary care public sector hospitals (around the country), were screened for depression and suicidal ideation/intent. Then, 352 patients were scrutinized who reported suicidal ideation or intent and scored significantly to depression (HAM-D).All those patients $(n=196)$ were included in the sample, who met the criteria of (1) age limit not less than 14 years, (2) No past psychiatric history, (3) not taking any psychotropic or not receiving any psychiatric treatment, (4) at least third time visiting the hospital for any active somatic complaint, (5) depressive symptoms are not characterized by any medical condition (ruled out via medical test, X-Rays, Ultrasounds, ECG, EEG etc.) and (6)presenting suicidal behavior which is not because of general medical condition. Residual patients $(\mathrm{n}=156)$ were redundant from the study who crossed the inclusion criteria and appropriate referrals have been made for these patients. Recruited patients have been provided with the inform consent, approved by ethical committee.

\section{Measures}

\section{Demographical Profile Sheet}

Demographics included Age, Gender, Marital Status, Employment type and Residence status. Furthermore, these variables were analyzed for exploring their correlation with the outcome measure.

\section{Hamilton Rating Scale for Depression (HAM-D)}

The Hamilton Rating Scale for Depression (Hamilton, 1996),is a 17-items questionnaire which is used to score patient's level of depression. HAM-D assess the severity of core symptoms of depression (depressed mood, feeling of guilt, suicide, insomnia, work and interest, retardation, agitation, anxiety, somatic and genital symptoms, weight loss, insight and diurnal variation). Although HAM-D contains 21-items but the scoring is based on the first 


\section{Un-Diagnosed Depression with Suicidal Ideation/Intent among Patients Visiting Medical OPD: Depression in Disguise}

17-items. Eight items are scored on a 5-point scale, ranging from 0 (not present) to 4 (severe). Nine are scored from 0 (not present) to 2 (moderate). The validity and reliability of HAM-D was confirmed by Hamilton (1960) who developed and used it as a clinical instrument.

\section{The Suicide Behaviors Questionnaire-Revised (SBQ-R)}

Based on Linehan et al., (1981) approach for the assessment of suicidal behavior, Osman et al., (2001)introduced a revised version SBQ, which is a brief self-report measure of past suicidal behavior. SBQ-R consisted of 4 items; each covers a different dimension of suicide. Total score range is 3-18 and the most useful cutoff scores on the SBQ-R are 7 for non-suicidal samples, and 8 for clinical samples. Both the single SBQ-R Item 1 and SBQ-R total scores are recommended for use in clinical and nonclinical settings. Due to the wording of the four SBQ-R items, a broad range of information is obtained in a very brief administration. Responses can be used to identify at-risk individuals and specific risk behaviors.

\section{Procedure}

After rigorous and careful procedure of selecting patients, we used the protocols for initial screening. It was basically a subjective and objective way of assessment, verbal and non-verbal gestures has been recorded and confidentiality and privacy has been assured to the participants. Initial assessments were done by research assistants before psychiatricOPD referral has been made. These referred cases were then re-assessed by the mental health professionals (i.e. teams of psychologist and psychiatrist), detailed interviews were done using CIS-R (Clinical Interview Schedule-Revised) and post-HAM-D (Hamilton Rating Scale for Depression), then they were inducted in the intervention programs based on the severity of the symptoms.

\section{RESULT}

\section{Description of the Sample:}

Study sample comprised of 156 men (20.8\%) and 594 women (79.2\%) with mean age 37 years and 14.2 SD. Categories based on age indicates that 29.1\% were $19-29$ years old, $25.7 \%$ were 30 40 years old, $22.9 \%$ were $41-51$ years old, only 5.5\% were less than 18 years old (18-14 years) and $8.3 \%$ were above 62 years. Marital status indicate $66.1 \%$ were married, $21.6 \%$ were single 8.4\% were widowed, 3.2\% were divorced and only 1\% were separated. Employment rate shows that $64.4 \%$ were house-person as the largest portion of the sample were women, $15.6 \%$ were doing full time job, 9.6\% were students, $4.9 \%$ were doing part time job, $2.8 \%$ were unemployed and $2.7 \%$ were retired. Residential inquiry shows that $57.1 \%$ had their own house, $36.8 \%$ were tenant, $4.4 \%$ were living with relative/friend, $1.2 \%$ were living in hostels and very small ratio $0.3 \%$ were homeless or unspecified residence. 


\section{Psychometric Evaluation of Measures (Preliminary Analysis):}

Reliability analysis indicated high magnitude of Cronbach's alpha coefficient on total scores of The Suicide Behaviors Questionnaire-Revised (SBQ-R), i.e., 0.89 indicating the internal consistency of the items.

Table 1: Means, standard deviations, Cronbach's Alpha Reliability Coefficients, Skewness and Correlation Coefficients on Scores of the Suicide Behaviors Questionnaire-Revised $(N$ = 750)

\begin{tabular}{lllllll}
\hline Scale & Mean & SD & Cronbach's Alpha & Skewness & No. of items & $\boldsymbol{r}$ \\
\hline HAM-D & 15.4 & 9.2 & 0.79 & 0.04 & 17 & $.284^{* *}$ \\
SBQ-R & 5.35 & 4.02 & 0.89 & 1.25 & 4 & -- \\
\hline
\end{tabular}

**. Correlation is significant at the 0.01 level (2-tailed).

Table 1 shows means, standard deviations \& alpha reliability of both the scales (HAM-D and SBQ-R). The reliability analysis shows that both of the scales are highly reliable. HAM-D has 0.79 reliability whereas 0.89 was the reliability of SBQ-R which is highly significant.

\section{Prevalence of Suicidal Behavior and Rate of Depression}

A recent study published in the January 2015 issue of the Journal of the American Academy of Child and Adolescent Psychiatry reported that MDD is highly prevalent in adolescents, whether measured over lifetime (11\%) or past year (7.5\%). Prevalence rates of MDD increased across adolescence and females 2-3-fold greater rates than males. The majority of adolescents with MDD demonstrated severe role impairment and substantial co morbidity with other mental conditions.

Table 2: Prevalence of Suicidal ideation or Intent and Rate of Depression

\begin{tabular}{llllll}
\hline Variable & Categories $\boldsymbol{n}$ & Prevalence per 10,000 persons & $\begin{array}{l}\boldsymbol{n} \text { (Rate } \\
\text { Depression ) }\end{array}$ & of \\
\hline Suicide & Case & 196 & $14.7 \%$ & $291(21.8 \%)$ & \\
& Non-Case & 554 & --- & 459 & \\
\hline
\end{tabular}

For this study we have calculated the prevalence rate of suicide and depression and the analysis of the data revealed that Total number of cases was 750 out of which 196 were having suicidal ideation or intent and its prevalence is $14.7 \%$. Secondly, 291 cases had depression which equals to $21.8 \%$ of the whole sample.

Table 3 shows the demographics of the study. Out of the 196 suicidal patients 26 (13.3\%) male and 170 (86.7\%) females reported their suicidal ideation/intent. Significant findings were found on gender, age and employment status. Based on analysis it is reported that females had more 


\section{Un-Diagnosed Depression with Suicidal Ideation/Intent among Patients Visiting Medical OPD: \\ Depression in Disguise}

suicide intent than males. On age variable, young people (19-29 years) had more suicide intent i.e. $35.2 \%$. Employment variable indicated that majority of the individuals were house person (65.3\%) we had the large number of having suicide ideation/intent. The last 2 variable of residence and marital status findings were not significant but according to the study majority of the patients were married (65.3\%) and 52.6\% were living in their own house which comprises of the majority of the data.

Table 3: Descriptive Analysis of Demographic Profile about the Participant’s Suicidal Behavior

\begin{tabular}{|c|c|c|c|c|c|}
\hline \multirow[t]{2}{*}{ Variables } & \multirow[t]{2}{*}{ Categories } & \multicolumn{4}{|c|}{ Stigmatization $(N=90)$} \\
\hline & & $\bar{n}$ & $\%$ & Chi-square & $p$ \\
\hline \multirow{7}{*}{ بِ } & Male & 26 & 13.3 & \multirow{3}{*}{9.14} & \multirow{3}{*}{0.00} \\
\hline & Female & 170 & 86.7 & & \\
\hline & $<18$ years old & 14 & 7.1 & & \\
\hline & $19-29$ years of age & 69 & 35.2 & \multirow{4}{*}{13.582} & \multirow{4}{*}{0.02} \\
\hline & $30-40$ years of age & 56 & 28.6 & & \\
\hline & $41-51$ years of age & 34 & 17.3 & & \\
\hline & $52-62$ years of age & 13 & 6.6 & & \\
\hline$\check{D}_{0}$ & $>62$ years old & 10 & 5.1 & \multirow{7}{*}{6.648} & \multirow{8}{*}{0.16} \\
\hline \multirow{7}{*}{ 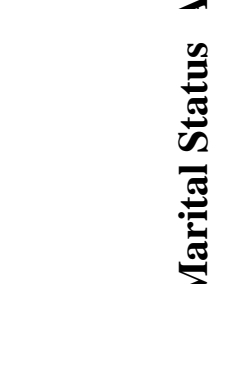 } & Married & 129 & 65.8 & & \\
\hline & Single & 40 & 20.4 & & \\
\hline & Separated & 3 & 1.5 & & \\
\hline & Divorced & 10 & 5.1 & & \\
\hline & Widow/widowed & 14 & 7.1 & & \\
\hline & Full time employed & 22 & 11.2 & & \\
\hline & Part time employed & 15 & 7.7 & \multirow{5}{*}{10.74} & \\
\hline \multirow{6}{*}{ 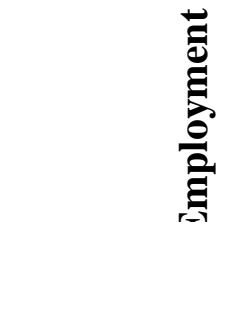 } & Student & 18 & 9.2 & & \multirow{4}{*}{0.05} \\
\hline & Retired & 4 & 2.0 & & \\
\hline & House person & 128 & 65.3 & & \\
\hline & Unemployed & 9 & 4.6 & & \\
\hline & Living in their own house & 103 & 52.6 & \multirow{5}{*}{8.882} & \multirow{5}{*}{0.11} \\
\hline & Living as tenant & 77 & 39.3 & & \\
\hline \multirow{3}{*}{ 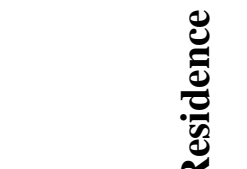 } & Living with relative or friend & 11 & 5.6 & & \\
\hline & Hostel resident & 3 & 1.5 & & \\
\hline & Others & 2 & 1 & & \\
\hline
\end{tabular}

\section{DISCUSSION}

Several studies indicate that depression is one of the most commonly encountered psychiatric illnesses in primary care settings. Yet, depression consistently goes undetected and undiagnosed 


\section{Un-Diagnosed Depression with Suicidal Ideation/Intent among Patients Visiting Medical OPD: Depression in Disguise}

by non-psychiatrically trained primary care physicians (Peruzzi, Canapary, Bongar, 1996). This study was aimed to calculate the prevalence rate of suicide among those who regularly visit the medical OPD due to psychosomatic concern. Results show that the prevalence rate of suicide is $14.7 \%$. WHO (2000) reports that more males commit suicide than females but more females attempt suicide. The suicide rate has two peaks: (a) the young (15 - 35 years) (b) the elderly (over 75 years). Divorced, widowed and single people are at a higher risk than married people. Those who live alone or are separated are more vulnerable. Loss of a job, rather than the status of unemployed persons, has been found to be associated with suicide. (WHO Report, 2000).

\section{Suicide Rate \& Gender:}

Gender is considered as a significant variable explaining rate of suicide as there is irregular pattern of attempted and committed suicides between males and females (Richard, 1994), which is called gender paradox of suicidal behavior and it varies across the world(Canetto, Sakinofsky, 1998). Evidences suggest that males die by suicide more commonly than females however, reported suicide attempts and suicidal ideation are more common in females than in males (Suicide.org, 2005; Crosby, Han, Ortega, Parks \& Gfoerer, n.d), and it is also supported by present study findings. China has very high suicide rate among females, especially young women in rural areas (Cheng \& Lee, 2000).

Suicide in Pakistan has been a long-term social issue and is a common cause of unnatural death. Incidents of suicide are often reported in the press and newspapers throughout the country as well as by several non-governmental organizations. However, diagnosing and covering suicide cases has generally been difficult in the local culture due to a number of social stigmas and legal issues that bind the problem; given that suicide is prohibited in Islam, there are various obstacles which come along in openly discussing the phenomenon in Pakistan, a predominantly Muslim country (Khan, Hashim, 2000). Suicide is considered a criminal offence, with punitive laws imposed in place for attempted suicide. National suicide statistics are not compiled on a formal level nor officially reported to the WHO, thus leaving any obtained data to be neglected and underreported (Khan, 1998). While suicide patterns have traditionally been low, there has been a slow but steep increase in the past few years.

One analysis of suicide reports, based over a period of two years, showed over 300 suicidal deaths in Pakistan from 35 different cities (Khan, Hashim, 2000). The findings showed that men outnumber women by 2:1 and that the majority of men who commit suicide tend to be unmarried; the trend for women, however, is the opposite. Research also indicated that the majority of subjects were under the age of 30 and that "domestic problems" are the main reason stated for suicide (Khan, Hashim, 2000). These include unemployment, health issues, poverty, homelessness, family disputes, depression and a range of social pressures. Hanging, use of insecticides and firearms are the most common methods for carrying out suicide in Pakistan

(Hassan, Sohaib, 2009). Review of the literature was conducted to better understand the (potential) role of mental health professionals in physician-assisted suicide. Noting the well- 


\section{Un-Diagnosed Depression with Suicidal Ideation/Intent among Patients Visiting Medical OPD: Depression in Disguise}

studied link between depression and suicide, it is necessary to question giving sole responsibility of assisting patients in making end-of-life treatment decisions to these physicians. Unfortunately, the use of mental health consultation by these physicians is not a common occurrence. Greater involvement of mental health professionals in this emerging and debated area is advocated. Beyond describing mental health professionals' role in the assessment of patient competency or decision making capacity, other areas of potential involvement are described. A discussion of ethical principles relevant to this area follows, along with comments on the training necessary to adequately serve patient needs (Peruzzi, Canapary, Bongar, 1996).

\section{CONCLUSION}

Current study was aim to assess Un-Diagnosed Depression with Suicidal Ideation or Intent among Patients Visiting Medical OPD. Mental health disorders (particularly depression) are associated with more than $90 \%$ of all cases of suicide. However, suicide results from many complex sociocultural factors. In current study Suicide by age are as follow, 35\% are from age range of 1929 years and $28.6 \%$ are aged of $30-40$ years. Youth suicide is increasing at the greatest rate. The study conducted in the US by the Centre of Disease Control and Prevention also supports the findings of the current study and reports that, overall suicide is the eleventh leading cause of death for all US Americans, and is the third leading cause of death for young people, age range of 15-24 years. Although suicide is a serious problem among the young and adults, death rates continue to be highest among older adults' ages 65 years and over. Males are four times more likely to die from suicide than are females. However, females are more likely to attempt suicide than are males.

\section{ACKNOWLEDGMENT}

The authors would like to thank the patients and their attendants for their serene participation in this study. We would like to thank the HODs (Medical Unit) of all hospitals who provided us a conducive environment for conducting this research project, we are deeply thankful to all medical officers, PGs and House officers who helped us a lot in the best of their capacity and capability. Last but not the least we are paying our sincere and utmost honor to Prof. Dr. Fareed A. Minhas, for being our constant source of appreciation, motivation and encouragement. Thanks to all latent entities that made this research possible.

\section{DECLARATION OF INTEREST \& FUNDING}

The author(s) declared no potential conflicts of interest with respect to the authorship and/or publication of this article and there is no funding involved in this research project by any organization. 


\section{Un-Diagnosed Depression with Suicidal Ideation/Intent among Patients Visiting Medical OPD:

\section{REFERENCES}

Anderson, R. N., Kochanek, K. D., \& Murphy, S. L. (1997). Report of final mortality statistics. Monthly vital statistics report. Hyattsville, Md: National Center for Health Statistics.

Beck, A. T., \& Steer, R. A. (1991). Manual for Beck scale for suicidal ideation. New York: Pennsylvania Corporation.

Beck, A. T., Steer, R. A., Kovacs, M., \& Garrison, B. (1985). Hopelessness and eventual suicide: A 10-year prospective study of patients hospitalised with suicide ideation. Am J Psychiatry, 142, 559-63.

Bertolote, J. M., Fleischmann, A., \& Leo, D. D. (2003). Suicide and mental disorders: Do we know enough? Br J Psychiatry, 183, 382-3.

Canetto, S. (1998). The Gender Paradox in Suicide. Suicide and Life Threatening Behavior, 28(1), 1-5. doi:10.1111/j.1943-278X.1998.tb00622.x.

Cheng, A. T. A., \& Lee, C. S. (2000). Suicide in Asia and the far eas. In K. hawton\& C. Van Heeringen (Eds.), The international handbook of suicide and attempted suicide (pp. 121135). Chichester: John wiley\& Sons.

Crosby, A.E., Han, B., Ortega, L. A. G., Parks, S. E., \&Gfoerer, J. (2011). Suicidal thoughts and behaviors among adults aged $\geq 18$ years-United States, 2008-2009. MMWR Surveillance Summaries. 60(no. SS-13).

Dannenberg, A. L., McNeil, J. G., Brundage, J. F., Brook-meyer, R. (1996). Suicide and HIV infection. Mortality follow-up of 4147 HIV-seropositive military service applicants. JAMA, 276, 1743-6.

Doyle, B. B. (1990). Crisis management of the suicidal patient. In S. J. Blumenthal, \& D. J. Kupfer (Eds.), Suicide over the life cycle: risk factors, assessment, and treatment of suicidal patients (pp. 381-423). Washington, DC: American Psychiatric Press.

Fawcett, J., Clark, D. C., \& Busch, K. A. (1993). Assessing and treating the patient at risk for suicide. Psychiatr Ann, 23, 244-55.

Finch, E. J. L., Ramsay, R., \&Katona, C. L. E. (1992). Depression and physical illness in the elderly. ClinGeriatr Med, 8, 257-87.

Fisher, B. J., Haythornwaite, J. A., \&Heinberg, L. J. (2001). Suicidal intent in patients with chronic pain. Pain, 89, 199-206.

Goldney, R. D., Winefield, A. H., Tiggemann, M., Winefield, H. R., \& Smith, S. (1989). Suicidal ideation in a young adult population. ActaPsychiatrScand, 79, 481-9.

Hamilton, M. (1960). A rating scale for depression. Journal of Neurology, Neurosurgery, and Psychiatry, 23, 56-62.

Harris, E. C., \& Barraclough, B. (1997). Suicide as an outcome for mental disorders: A metaanalysis. Br J Psychiatry, 170, 205-28.

Hassan, Sohaib. (2009). Suicide Prevention in Pakistan. Retrieved from http://en.wikipedia.org/wiki/Suicide_in_Pakistan on 08th April, 2015.

Hawton, K. (1987). Assessment of suicide risk. Br J Psychiatry, 150, 145-53. 


\section{Un-Diagnosed Depression with Suicidal Ideation/Intent among Patients Visiting Medical OPD: Depression in Disguise}

Hendin, H., Maltsberger, J. T., \& Haas, A. P. (2004). Desperation and other affective states in suicidal patients. Suicide Life Threat Behav, 34, 386-94.

Henriksson, M. M., Aro, H. M., Marttunen, M. J., Heikkinen, M. E., Isometsa, E. T., \&Kuoppasalmi, K. J. (1993). Mental disorders and comorbidity in suicide. Am J Psychiatry, 150, 935-40.

Ikeda, R. M., Kresnow, M. J., \& Mercy, J. A. (2001). Medical conditions and nearly lethal suicide attempts. Suicide Life Threat Behav, 32(1), 60-7.

Kaplan, A., \& Hollander, E. (2003). A review of pharmacologic treatments for obsessivecompulsive disorder. PsychiatrServ, 54, 1111-8.

Khan, M. M. (1998). Suicide and attempted suicide in Pakistan. Crisis, 19(4), 72176. doi:10.1027/0227-5910.19.4.172.PMID 10331315.

Khan, M. M., Reza, Hashim, (2000). The pattern of suicide in Pakistan. Crisis, 21(1), 3135. doi:10.1027//0227-5910.21.1.31. PMID 10793469.

Koenig, H. G., Meador, K. G., Cohen, H. j., \& Blazer, D. G. (1988). Depression in elderly hospitalised patients with medical illness. Arch Intern Med, 148, 1929-36.

Linehan, M., \& Nielsen, Stevan, L. (1981). Assessment of suicide ideation and para-suicide: Hopelessness and social desirability. Journal of Consulting and Clinical Psychology, 49(5), 773-775.

Mackenzie, T. B., \&Popkin, M. K. (1987). Suicide in the medical patient. Int J Psychiatry Med, 17, 3-22.

Mann, J. J., Waternaux, C., Haas, G. L., \& Malone, K. M. (1999). Toward a clinical model of suicidal behavior in psychiatric patients. Am J Psychiatry, 156, 181-9.

Maris, R. W. (2002). Suicide. Lancet, 360, 319-26.

Marzuk, P. M. (1991). Suicidal behavior and HIV illnesses. Int Rev Psychiatry, 3, 365-71.

Moscicki, E. K. (1997). Identification of suicide risk factors using epidemiologic studies. PsychiatrClin North Am, 20, 499-517.

Murphy, G. E. (1975a). The physician's responsibility for suicide. I. An error of commission. Ann Intern Med,82(3), 301-4.

Murphy, G. E. (1975b). The physician's responsibility for suicide. II. Errors of omission. Ann Intern Med, 82(3), 305-9.

Norris, J. T., Gallagher, D., Wilson, A., \&Winograd, C. H. (1987). Assessment of depression in geriatric medical outpatients: the validity of two screening measures. J AmerGeriatrSoc, 35, 989-95.

Okimoto, J. T., Barnes, R. F., \&Veith, R. C. (1982). Screening for depression in geriatric medical patients. Amer J Psychiatr, 139, 6-9.

Osman, A., Bagge, C. L., Guitierrez, P. M., Konick, L. C., Kooper, B. A., \&Burrios, F. X. (2001). The Suicidal Behaviors Questionnaire Revised (SBQ-R). Validation with clinical and nonclinical samples. Assessment, 5, 443-454.

Palsson, S., \& g, I. (1997). The epidemiology of affective disorders in the elderly: a review. IntClinPsychopharmacol, 12 (7), S3-S13. 
Peruzzi, N., Canapary, A., \&Bongar, B. (1996). Physician-assisted suicide: the role of mental health professionals. EsthicsBehav, 6(4), 353-66.

Rich, C. L., Young, D., \& Fowler, R. C. (1986). San Diego suicide study. I. Young vs old subjects. Arch Gen Psychiatry, 43, 577-82.

Suicide Statistics at Suicide.org. (2005). Suicide prevention, awareness, and support.

Udry, J. R. (1994). The Nature of Gender. Demography, 31 (4), 561-573. doi:10.2307/2061790. JSTOR 2061790. PMID 7890091.

World Health Organization. (2002). Multisite intervention study on suicidal behaviors, SUPREMISS. Geneva.

World Health Report. (2001). Mental Health: New Understanding, New Hope. Geneva: WHO

Zimmerman, M., Lish, J. D., Lush, D. T., Faber, N. J., Plescia, G., \&Kuzma, M. A. (1995). Suicidal ideation among urban medical outpatients. J Gen Intern Med, 10, 573-6. 